\title{
QUAIS AS RAZÕES PARA A VIOLÊNCIA ENDÊMICA NO ORIENTE MÉDIO E MUNDO MUÇULMANO?
}

Peter R. Demant

Ariel Finguerut

0 grande Oriente Médio majoritariamente muçulmano, desde há muito a região mais complexa do mundo, está hoje mais do que antes rasgado por uma cadeia de guerras, guerras civis e violentas tensões intra- e inter-estatais. 0 sexto número da Revista Malala, produção do Grupo de Trabalho Oriente Médio e Mundo Muçulmano do Laboratório de Estudos da Ásia (LEA FFLCH-USP), é dedicado ao tema da Violência no Oriente Médio e Mundo Muçulmano contemporâneo. Nosso enfoque está nas diversas modalidades de violências - política, religiosa, étnica - e de revoluções. Quais as razões para a violência endêmica no Oriente Médio e Mundo Muçulmano? Ela é aparente ou real? Quais suas dimensões e especificidades históricas, sociológicas ou mesmo psicológicas? Em sua seção de debates a Revista propõe discutir a violência na região (causas, consequências e atores) e seus efeitos diretos sobre os muçulmanos. Para tanto, quatro eixos articulados a esse grande tema foram propostos:

\section{Refugiados, crise política europeia e o papel das Organizações Políticas Internacionais.}

A atual crise de refugiados é das mais graves da história contemporânea europeia. Partidos nacionalistas com retórica anti-imigrantes como o húngaro Jobbik, liderado por Gabór Vona, e a Aurora Dourada, na Grécia, se aproximam da definição clássica de partidos neofascistas ou de extrema-direita. Contudo, como chama atenção o pesquisador da extrema direita francesa Jean-Yves Camus, partidos como o Front National de Marine Le Pen na França, o Vlaams Belang em Flandres e o Partido da Liberdade na Áustria (FPÖ) não se encaixam na definição clássica de extrema-direita e não exatamente ganharam espaço ou chegaram ao poder com o agravamento da crise. Governos de centro-direita como a Dinamarca de Lars L. Rasmussen ou mesmo a Alemanha de Angela Merkel (líder da União Democrata-Cristã) ou a Holanda - cujo parlamento será dirigido pela trabalhista Khadija Arib (muçulmana, nascida no Marrocos) - estão se fechando para novos refugiados. Eles temem os distúrbios sociais e culturais, além do custo para o Estado, que a chegada dessa população acarreta. Como enfrentar tal crise?

Muitas feministas e ONGs europeias apontam que as mulheres muçulmanas são frequentemente subjugadas, sofrendo violências cotidianas e estruturais e que essa situação poderia ser transportada para a Europa e, consequentemente, para as mulheres europeias. Há intenso debate sobre como evitar ataques a mulheres - ataques que já 


\section{apresentação}

aconteceram em 2016. Deveriam imigrantes ou refugiados muçulmanos fazer "cursos" que entre outras coisas se preocupam em "ensinar" como tratar mulheres europeias? E como lidar com incidentes homofóbicos e antissemitas que ocorrem entre certos refugiados? São estas medidas as melhores alternativas para combater a violência contra a mulher?

Por outro lado, movimentos como o alemão Pegida - em português: Europeus Patrióticos contra a Islamização do Ocidente, que no começo de 2015 realizou grandes manifestações em várias cidades alemãs - parecem generalizar o problema e fomentar a islamofobia. Quais os desdobramentos desses movimentos europeus?

Diante da crise política dos refugiados, podemos concluir que organizações políticas como as Nações Unidas ou mesmo a União Europeia perderam sua relevância?

\section{Sectarismo no Islã: nuances, usos e desdobramentos.}

Temos observado diversos conflitos entre grupos sectários dentro do islã. Esses conflitos perpassam zonas de guerras como a Síria, o Iêmen e o Iraque. De um lado, temos, por exemplo, o wahabismo sunita. Há os salafistas - que em alguns aspectos pouco se diferenciam dos wahabistas - que, também sunitas, detém forte presença no Norte da África; e finalmente o próprio Estado Islâmico, que defende um Califado, e que muitas vezes se coloca como uma força protetora anti-xiita dos sunitas. De outro lado tem-se o Irã, uma potência regional importante, com o "governo dos juristas islâmicos" ou fiqh, cuja postura oficial muitas vezes defende abertamente os xiitas. 0 que esses movimentos sectários nos mostram sobre as causas, as motivações e as justificativas para a violência no Oriente Médio e no Mundo Muçulmano? Como enfrentá-los? Por que movimentos "conservadores" como o wahabismo e o salafismo crescem entre muçulmanos no Ocidente? E mesmo sob repúdio generalizado, o Estado Islâmico segue recrutando muçulmanos. Como frear esse processo? E como entender o Irã, que segue jogando seu xadrez geopolítico persa, tendo muitas vezes como adversário os sauditas e/ou turcos e cuja política externa muitas vezes é ambígua - especialmente diante do Ocidente? O Irã é um aliado contra o radicalismo islâmico ou um patrocinador? E os países do Golfo?

\section{A Guerra na Síria e o reordenamento dos atores locais, regionais e globais.}

O Estado Islâmico, formado por uma grande rede de pequenos grupos jihadistas, sem deixar de ter uma tendência centralizadora, apresenta, muitas vezes, um discurso de combate não aos críticos ao islã - mas, sobretudo, um discurso que aponta para a hipocrisia de certos líderes ou de governos de países muçulmanos que "não seriam de fato muçulmanos". O Estado Islâmico propõe uma nova visão de comunidade e de inserção social dos muçulmanos. A Síria, mergulhada já há cinco anos numa Guerra Civil - com cerca de 250 mil mortos e 11 milhões de refugiados e deslocados internos - é palco de discursos sectários e de conflitos motivados por acusações de intolerância e de violência étnico-religiosa. 
Por um lado estão as forças fiéis a Bashar al Assad apoiadas por Rússia, Irã e o Hezbollah (grupo xiita libanês com braço militar). Do outro lado, Turquia (com quase 2 milhões de refugiados), Arábia Saudita e seus aliados do Golfo Pérsico. No centro, o Estado Islâmico, alvo de uma coalizão militar aérea com participação dos EUA, mas que ainda controla territórios importantes e ainda é capaz de realizar ataques terroristas no Ocidente. A situação síria mergulha numa geopolítica cada vez mais delicada. Um "efeito dominó" poderia envolver as grandes potências em um novo conflito de grandes proporções? 0 que esperar dos EUA? E da Turquia? Rússia? ONU? União Europeia? Podemos esperar outros cinco anos de conflito?

Em seu discurso ao Estado da União em 2016, Barack Obama demonstrou preocupação com o conflito, contudo, deixou claro que se trata de uma ameaça internacional e não propriamente uma ameaça à segurança nacional dos Estados Unidos. A superpotência do século XXI teria perdido sua capacidade de hegemonia? Quais são as possíveis soluções para a Guerra na Síria? Como explicá-la? E, diante dos rumos tomados, quais suas possíveis consequências e desdobramentos?

\section{Cultura de Paz e o Radicalismo Religioso.}

Quais são as contribuições da chamada "cultura de paz" nos desdobramentos e acontecimentos da política internacional? É possível combater o recrutamento de novos jihadistas? Há experiências que podem evitar novos "homens e mulheres bomba"? Como funcionam as ONGs, grupos ou movimentos civis que focam na estratégia de persuasão anti-fundamentalismo religioso? Há casos de sucesso dentro do islã? Podem eles ser a chave para, de fato, derrotar o Estado Islâmico e ir além, desqualificando discursos sectários que alimentam conflitos entre, por exemplo, xiitas e sunitas ou entre religiosos/ conservadores e moderados/liberais?

Tais quatro grandes eixos nortearam nossa busca por pesquisas e reflexões para composição deste sexto número. As contribuições e produções recebidas não abarcam todas as questões propostas, mas em geral dão conta daquelas temáticas e perspectivas mais divulgadas e estudas no Brasil. A entrevista do professor Tullo Vigevani nos faz refletir sobre as causas filosóficas e políticas da violência, remetendo-nos à necessidade de prevalência da política e da compreensão do outro. 0 ensaio do professor Peter Robert Demant desenvolve uma discussão comparativa sobre as recentes contribuições intelectuais em termos das análises e estratégias para lidar com o terrorismo. 0 fato da maioria dos intelectuais - de um lado ao outro do espectro - não estar comprometida com o verdadeiro entendimento das causas do terrorismo jihadista demonstra a patente incapacidade da academia - e porque não também da classe política - em propor alterativas eficazes para o combate ao fenômeno. 


\section{apresentação}

O artigo de Beatriz Buarque traz um estudo sobre a violência do Estado Islâmico contra mulheres e meninas yazidis e seu sistema de escravidão sexual, focado principalmente sobre esta comunidade. O texto de Ananda Vilela da Silva Oliveira discute as diversas mudanças sociais, culturais e econômicas sendo vivenciadas pelo Oriente Médio, e de que forma se relacionam com problemáticas tais como inserção internacional, intervenções, integração e resistências. 0 artigo de André Aprígio e Isabel Estrada Carvalhais discorre sobre os desafios contemporâneos das teorias de segurança sob a visão europeia em seu enfrentamento das chamadas "novas ameaças", sobretudo as virtuais e ligadas ao Estado Islâmico.

O relato de campo de Victor Begeres Bisneto compila suas experiências com refugiados sírios em Campinas que buscam no Brasil um local de sobrevivência e refúgio de uma guerra que já dura cinco anos. Baseado em relatos orais recolhidos de Setembro a Novembro de 2015, Victor concentra-se na visão destas imigrantes sobre o conflito sírio e no papel que conferem às potências atuando no país. 0 relato de campo de Flávia Andréa Pasqualin e Francirosy Campos Barbosa apresenta uma parte do movimento Hizmet no Brasil, visando compreender o fenômeno do casamento intercultural. 0 estudo é feito através da pesquisa de campo etnográfica (presencial e virtual) das famílias turcas e mistas (compostas por brasileiras casadas com muçulmanos turcos) vivendo no país.

A resenha de Augusto Veloso Leão da obra de Paul Aarts e Carolien Roelants Saudi Arabia: a kingdom in peril debate de que modo se compõem as forças conservadoras e progressistas no país. Os desafios sendo enfrentados pela monarquia wahhabita parecem colocar seu reino em perigo, mas estão longe de verdadeiramente minarem a estabilidade deste sistema - ao menos por hora. Luciana Eliza dos Santos elabora uma resenha do filme Cinco Câmeras Quebradas do palestino Emad Burnat e do israelense Guy Davidi. Esta contribuição novamente resgata o tema das formas de resistência, da relação com o território e do belicismo. Mas também da (re)acomodação, das manifestações pacíficas em Bil'in e do conhecimento ocidental sobre a realidade palestina. Finalmente, o perfil intelectual de Edward Said por Danilo Guiral Bassi encerra este número de forma circular, retornando ao seu princípio: à necessidade de compreensão do outro, da realidade dos intercâmbios e interdependências de nosso tempo, do exercício de alteridade e da ênfase na proposta humanista saidiana.

São Paulo, Julho 2016 